\title{
TELL ME A STORY: DEVELOPING A MOOC PEDAGOGY
}

\author{
Aidan Johnston \\ ${ }^{1}$ University of Strathclyde (SCOTLAND)
}

\begin{abstract}
In January 2014, The University of Strathclyde ran the institution's first the Massive Open Online Course (MOOC) "Introduction to Forensic Science" on the FutureLearn platform which is operated by The Open University. The course had over 26,000 enrolments with participants from 130 countries. This MOOC taught the fundamental principles of forensic science supported by a filmed murdermystery "Murder on the Loch" with episodes of the case study revealed in short video segments each week. Each week forensic science concepts e.g. fingermarks, drugs, DNA were introduced and related to the unfolding crime case.
\end{abstract}

The murder-mystery story, being "believable, rememberable, and entertaining" (Neuhauser, 1993), underlined the second principle of the course - that of an underpinning of fun. This led the course to be developed with a conscious effort to engage participants in activities which were closely aligned to materials and learning outcomes but stimulated learners through enjoyable exploration outside of the course core website. Such activities included learning to take fingerprints, shoe impressions and participants extracting their own DNA. Such a combination of activities and storytelling proved a massive success, one we were extremely keen to replicate in future MOOC course design.

Storytelling has now inherently become the MOOC pedagogy at the University of Strathclyde. Building upon the success of our first and highly successful MOOC, the University of Strathclyde has worked hard over the past year to replicate this success by focusing on utilising storytelling in the pedagogical design of our newest MOOCs.

From a rogue computer virus that unleashes chaos worldwide in our 'Introduction to Journalism' MOOC where learners explore the key principles and debates in journalism and enact the role of a journalist in the context of an escalating story.

To the heart wrenching and hard hitting story of Billy, a vulnerable young boy and his mother Karen and the various care challenges they face. In this course, learners develop an understanding of some of the approaches involved in caring for vulnerable children.

Drawing upon learner feedback from our first $\mathrm{MOOC}$ and examining the lessons learned, I will outline how we have managed to grow our learner base from 27,000 learners to over 100,000+ learners in just over a year. By comparing and contrasting between the various MOOCs, I will explore the challenges and the opportunities each course has offered and how we are now attempting to apply our MOOC pedagogy into undergraduate course design at the University of Strathclyde.

\section{$1 \quad$ INTRODUCTION}

A story "facilitates instruction directly through verbal or linguistic means and indirectly by aiding in the mental construction of a sequence of events enacted for or by the learner" (Andrews, Hull \& Donahue, 2009).

In January and February 2014 University of Strathclyde ran the institution's first the Massive Open Online Course (MOOC) "Introduction to Forensic Science" on the FutureLearn platform. FutureLearn is a massive open online course (MOOC) learning platform founded in December 2012. It is a company launched and wholly owned by The Open University in Milton Keynes, England. It is the first UK-led massive open online course learning platform.

The first run of the course had 26,000 enrolments with participants from 130 countries. This MOOC taught the fundamental principles of forensic science supported by a filmed murder-mystery "Murder 
on the Loch" with episodes of the case study revealed in short video segments each week. Each week forensic science concepts e.g. fingermarks, drugs, DNA were introduced and related to the unfolding crime case. The course concluded with participants voting on the guilt or innocence of the primary suspect based on the analysis of the evidence provided in light of the forensic science principles covered. The ideas of MOOC retention and completion and what these entail and how they can be improved is controversial. However, the story-telling device was shown to be effective in retaining participants throughout the six weeks of the course with $28 \%$ of participants active in the first week still active in the final week. This can be compared with the reported typical completion rate of $7 \%$ (Jordan as cited by Parr, 2013).

The murder-mystery story, being "believable, rememberable, and entertaining" (Neuhauser, 1993), underlined the second principle of the course - that of an underpinning of fun. This led the course to be developed with a conscious effort to engage participants in activities which were closely aligned to materials and learning outcomes but stimulated students through enjoyable exploration outside of the course core website. Such activities included learning to take fingerprints, shoe impressions and participants extracting their own DNA.

The resulting course was therefore different in its developmental imperatives than many traditional campus-based courses. Run successfully as a MOOC, the course is now being run for a first year undergraduate course.

Building upon the success of the first $\mathrm{MOOC}$ and upon review of the course feedback it was clear that course participants enjoyed the storytelling element of the MOOC and in some cases they fed back that the story that weaved its was through the six weeks of the course was the hook that kept them coming back each week and encouraging them to complete the course.

\subsection{Overview of 'Introduction to Forensic Science' 2.1 Introduction}

The course addresses four major evidence types: drugs of abuse, DNA, firearms and impression evidence, and discusses these through the exploration of a case-based scenario presented across a six-week modular framework. A murder case set on the murky shores of Loch Lomond provided the backbone to 'Introduction to Forensic Science'. As the case unfolded each week, a number of evidence types, and the forensic science approaches that may be used to evaluate the evidence, are explored. In the first week the scene of the crime was set and participants looked at how the initial crime scene is processed. Subsequent weeks introduce various types of evidence including drugs of abuse, fingerprints, DNA, footwear marks and firearms. Course material is supplemented with opportunities to check understanding and engage with fellow learners, as well as the course leaders, who have international reputations in the field of forensic science. Participants are encouraged to formulate (and defend!) opinions on the case, based on their evaluation of the evidence.

\subsection{Anatomy of the Course Structure}

It is impossible to cover the whole of forensic science, even at an introductory level, in a six week MOOC. Rather than attempting that, we adopted a case-based approach which sets out the fundamental principles applying to any investigation where forensic science is involved. What participants see is a structured flow beginning in week one at the place where forensic science begins, namely the scene of the incident. The incident itself is the glue that binds the course as they move to explore four core but quite different examples of forensic science in weeks 2 to 5 , ending in week 6 with a review of how forensic science contributed to the investigation and closure of the case.

The course itself is divided into six weeks. These contain various activities that participants should aim to complete within the week, each one is built from a sequence of straightforward 'steps', to help them learn. Each week is given a descriptive name, so participants always know what's expected, and they can navigate between them, to see what's coming up, or catch up from the beginning if they are late starting the course.

Each week the course is then broken down further into individual 'steps', which should be worked through in order. Step activities include reading articles, watching videos, listening to audio, partaking 
in discussions and undertaking short end of week quizzes to help participants check that they have understood what they have learned.

At the end of key weeks of the course, weeks 1, 3 and 6, participants are given an opportunity to ask the course educators any questions they have relating to the course and indeed the 'Murder by the Loch' story. These events are known as Google Hangouts on Air. Google Hangouts on Air can be likened to being a fly on the wall in a video conference call. These events are not a mandatory part of the course, but can be a fun way to get to know the course leaders and fellow learners.

A Google Hangout on Air is a videoconference that is conducted using Google's Hangouts functionality, but also 'broadcast' to the public on YouTube, where it is automatically archived. A Google Hangout on Air is a great tool for bringing the course to life, and to create a sense of occasion. It's a rich but self-contained way for learners to communicate with you in real-time, and an opportunity to make best use of the short amount of time you might be able to get with a special guest who isn't normally available throughout the course. For the learners who can participate (either on camera or in the text chat) it's a chance to 'meet' the educators and other learners, who may be in very different locations and cultures around the world. Even for those who can't take part at the time, it can be a rewarding experience and strengthen the sense of community. A Google Hangout can also have an appeal beyond the learners on the course and if you have influential guests or topical subject matter to discuss, it can be an effective means of promoting the course and showcasing the educator's expertise more widely.

Each week is introduced by a short presentation from the lead educator, Professor Jim Fraser. Unlike some other FutureLearn courses, we opened the course a week at a time - part of the learning process is about reflecting on the direction our thinking is going and we don't want to spoil the examination of the case study by giving too much away too soon!

\section{Course structure - Telling the Story}

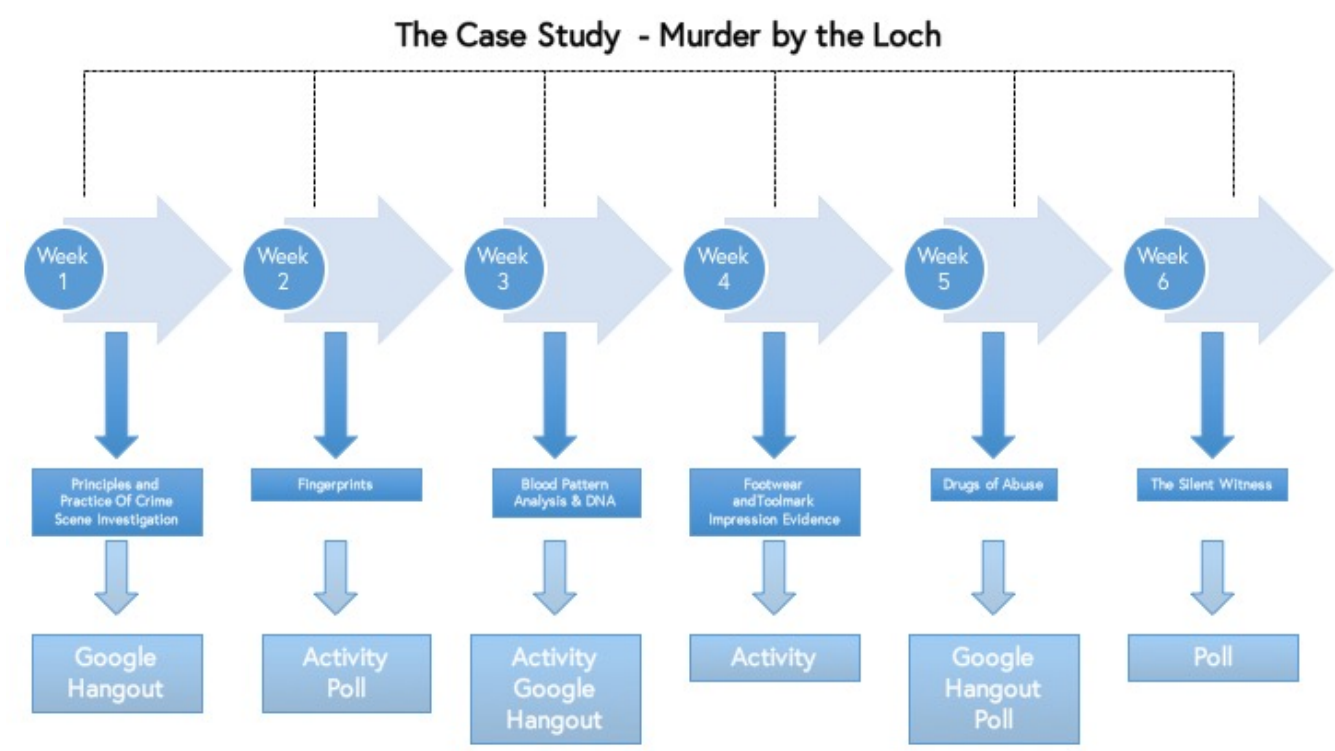

Figure 1 - Introduction to Forensic Science - Course Structure

As Figure 1 shows, the course structure comprises of the core MOOC steps and activities, these are then complimented with additional activities such as the Google Hangouts. Given that the nature of the course is scientific, we were keen to ensure that participants could actually undertake these activities at home themselves to help underpin the scientific theory they were learning about each week of the course.

These activities listed in figure 2 shows the theory explored in that week along with a corresponding activity. 


\begin{tabular}{|l|l|}
\hline \multicolumn{1}{|c|}{ Week number/Theory } & \multicolumn{1}{c|}{ Activity } \\
\hline 2. Fingerprints & $\begin{array}{l}\text { How to take you own fingerprints at home using } \\
\text { sticky tape, sharing your fingerprints with the } \\
\text { group and discussing further. } \\
\text { Voting poll. }\end{array}$ \\
\hline 3. DNA & How to take and extract your own DNA at home. \\
\hline 4. Footwear marks & $\begin{array}{l}\text { How to take and analyse your own footwear } \\
\text { marks at home. } \\
\text { Voting poll. }\end{array}$ \\
\hline 6. The Silent Witness & 'The Verdict': Guilty or not guilty voting poll. \\
\hline
\end{tabular}

Figure 2 - Introduction to Forensic Science - Course Activities

The feedback received from participants who undertook these activities was overwhelmingly positive, with many reaffirming how undertaking the activities had helped to strengthen their understanding of the theory explored in that week of the course and in many cases, the other weeks where no activities were made available. These simple activities made participants rethink the way they viewed science with some proudly declaring they were ably assisted by other members of their family and had lots of fun in the process.

At the end of each week, participants have a chance to reflect on their learning via 'what have you learned' steps. The purpose of these steps at the end of each week was to allow the participants to stop and reflect on their learning and share this with other course participants. It was a useful way for them to interact and support each other, often realising they all had similar observations and thoughts on the course and indeed the 'Murder by the Loch' story.

It was critical to the success of the course that each week a new discovery was uncovered in the case study story. One participant likened it to reading a good book, once you start, you can put it down and you want to continue to the end to find out who done it. In week six of the course, we allowed the participants to become judge, jury... and executioner. Like any good crime story, a court of law is usually a firm feature to help bring a sense of justice and closure to a story. We were keen to replicate this in the MOOC and we setup a Poll using a popular web polling website and put the question to the participants:

\section{"Do you find Mr Ward (the accused) beyond reasonable doubt guilty or not guilty of the murder of his wife Mrs Ward?"}

\subsection{Critical Success Factors of the MOOC Course Design}

We believe that the critical success factors in our MOOC design where storytelling plays a large part are as follows:

1. The importance of a strong narrative - this is provided by "Murder by the Loch" Case Study.

2. Active learning - evidenced through activities participants could undertake themselves at home e.g. how to take their own DNA, how to take their own fingerprints, footwear impressions.

3. Local context to learning - Steps where participants are tasked with examining practice in their locality. For example, a course activity where they research and discuss their own country's DNA database laws and practices.

4. Social learning - a vast range of diverse learners contribute opinions, discussion and peer support.

5. Interactive learning - three live audio-video "Google Hangouts" allow course educators to respond to identified areas of interest \& concern while taking follow-up questions live.

\subsection{Reflecting on success and next steps}

Upon completion of the MOOC, participants are encouraged to complete a 'post course survey'. This survey asks some personal questions about the participant, where they live and their opinions on the 
quality of the course, the course content, activities etc. There is also an option for them to leave free text feedback. Upon analysis of the feedback, it was evident to the course team that the storytelling element was crucial in determining the successful completion of the course to some participants.

Some of the comments have been listed below:

Participant ' $A$ ': This MOOC had everything and was a real 'page turner' waiting for weekly fix of whodunit. I mean how many online courses include a murder as part of the content.

Participant ' $\mathrm{B}$ ': An absolutely terrific course, I've been waiting every long winter week for Monday to come around to learn the next "skill" and find out how Murder at the Loch had developed. Thank you for such a superbly laid out course, it's been a credit to your university and your profession.

Participant 'C': Excellent course, really well put together, and thoroughly engaging - a good mix of clearly laid out theory, some fascinating and thought-provoking articles and videos, and a sprinkling of fun practical activities!

Participant 'D': You were all fantastic! A big thank you to each and every one of you. You all made this a very enjoyable, and interesting class. I wish classes had been taught like this when I was in school.

Subsequently, a MOOC rubric was developed within the University of Strathclyde with a view to attracting applications for future $\mathrm{MOOC}$ courses from the wider university community. Part of this rubric is explicit in encouraging applicants to include an element of storytelling as part of the course design. The rationale for including storytelling was in response to the overwhelming feedback and success of using storytelling in the design of our first MOOC.

\subsection{Storytelling in the 'Introduction to Journalism' MOOC}

The Introduction to Journalism course was aimed at those curious about journalism and looking to gain a better understanding of what the subject entails. The lead educators are a team of internationally-renowned scholars and journalism practitioners at the University of Strathclyde. The course offers a behind-the-scenes look at the professional world of reporters and editors. The course is divided into six weeks: what makes a good news story; writing news; writing features; opinion writing; politics and journalism; and investigative journalism - and explores these in relation to a storytelling narrative running throughout the six weeks as shown in figure 3.

Although the scenario employed entitled 'The Blackout' about a computer virus that causes chaos worldwide is entirely fictitious, participants engage in tasks and discussions that reflect real-life situations in journalism. Each week contains a variety of learning activities that introduces concepts, challenge assumptions, facilitate understanding and hone new skills. 


\section{Course structure - Telling the Story}

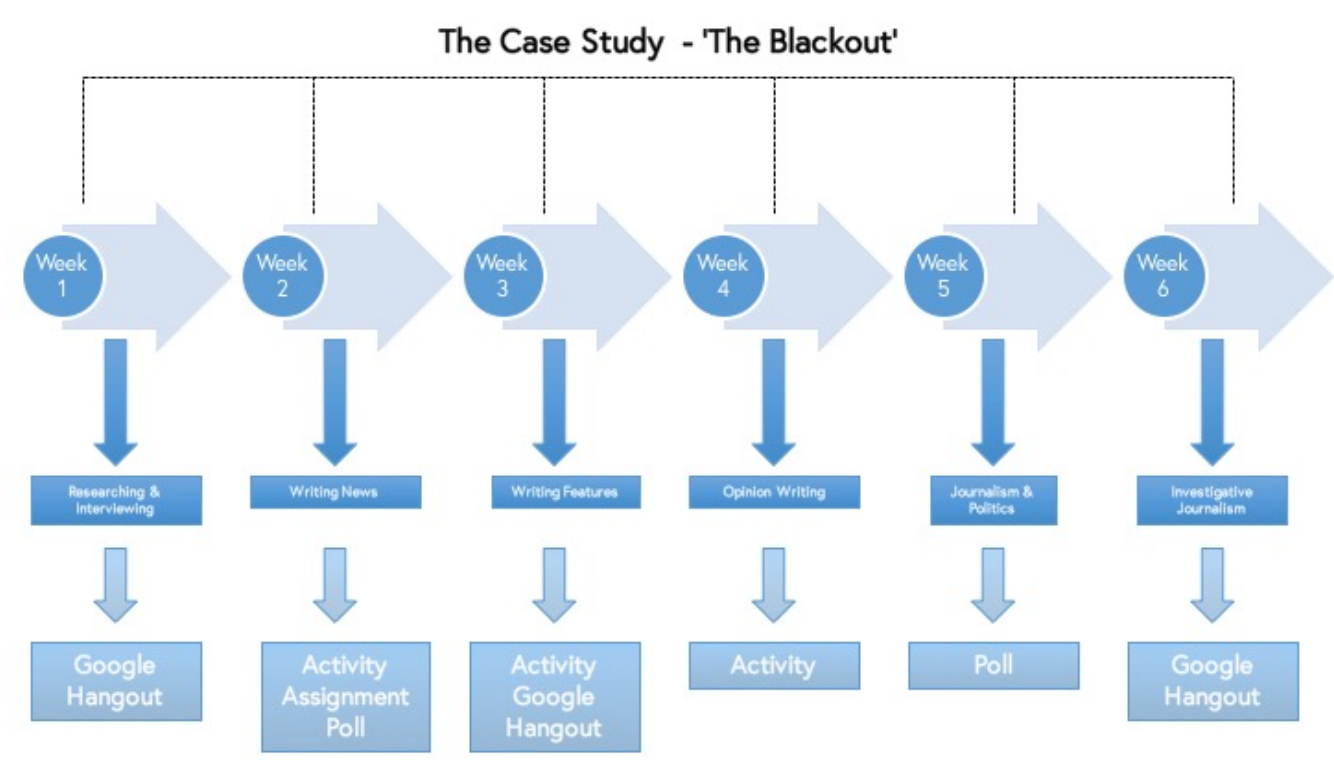

Figure 3 - Introduction to Journalism - Course Structure

Much like the 'Introduction to Forensic Science' MOOC, participants are encouraged to discuss their thoughts with peers and tutors, generate and edit small pieces of writing, and comment on others' work. Several esteemed journalists from around the world feature in each week of the course, as they discuss key topics in relation to their own work. By enacting the role of a journalist in the context of an escalating story, the course adheres to Strathclyde's ethos of "a place of useful learning."

\subsection{Storytelling in the 'Caring for Vulnerable Children' MOOC}

The third MOOC that was developed was entitled 'Caring for Vulnerable Children'. In times of austerity and shrinking public services, the task of identifying and caring for vulnerable children has never been more challenging. This MOOC explores some of the issues involved in undertaking this task.

The course examines what we mean by risk and vulnerability, as well as how we define good enough parenting. Participants are encouraged to think about how children grow and develop, and how we can provide them with containment and security via meaningful relationships and attachments. The course also examines particular skills involved in communicating with children and young people and the characteristics that define different methods of practice and how some approaches can help us to resist risk-averse thinking. Participants consider different possible interventions and how, in Scotland, this is managed within the Children's Hearing System. The course concludes by reflecting on the current politics of caring for vulnerable children in a context of budget cuts and increasing child poverty. 


\section{Course structure - Telling the Story}

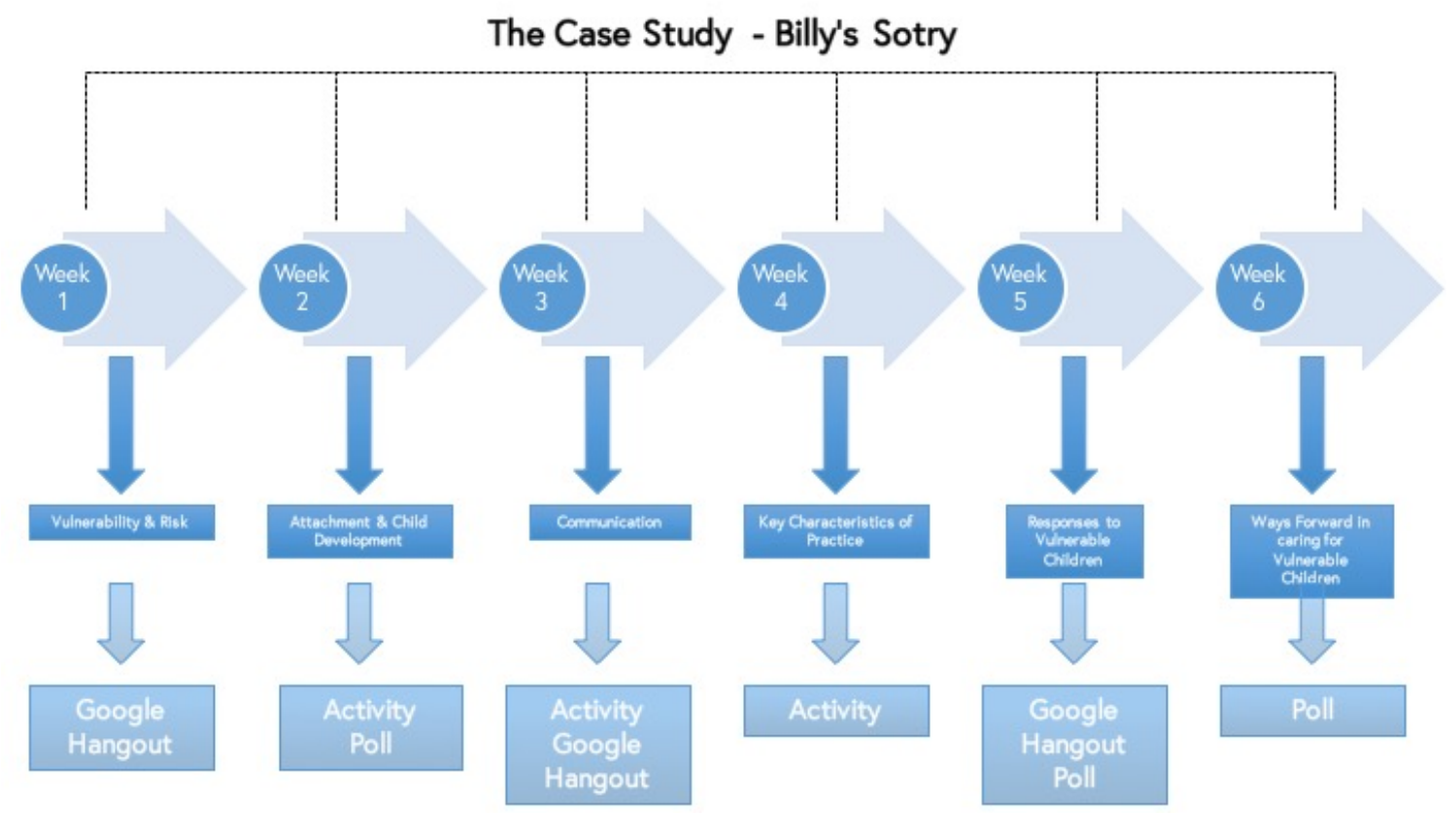

Figure 4 - Caring for Vulnerable Children - Course Structure

Through the course we use the story of a vulnerable child called Billy and the challenges he faces in his daily life all in context to the theory being explored each week in the course. In week six, and in a similar poll to the the 'guilty/not guilty vote' used in the 'Introduction to Forensic Science' MOOC, participants are asked to vote on whether they think that Billy should remain in the care of his mother or should he be removed from her care. Again, we saw similarities in the voting and feedback from participants in each of these courses. A wide range of emotions were expressed and opinions aired, all the while participants referring to specific things they have learned from the theory explored through the course and contextualising their decision based upon what they have read, discussed and watched throughout the course. Participants once again fed back via the post course survey about how much they enjoyed following his story and how it helped them to understand the various topics that they explored each week.

\section{Conclusions}

At this point in time, we have attracted over 100,000 enrolments to our MOOCs. I perceive that this is largely in part to the fact we have utilised the element of storytelling as part of the MOOC design here at the University of Strathclyde.

Valuable lessons have been learned with each new course that we develop and we actively reflect and act upon the feedback and experiences of our participants.

I believe that participants have modern expectations when it comes to their own learning and there are a variety of other elements, in addition to storytelling, that are important in the design of a good MOOC.

1. The element of fun in a course - like so much of their online activity, the learning process should be a fun one for the participants. Activities such as taking your own fingerprints at home, or making a mess and spending time with family members creating your own footmarks add to that element of fun in a course. 
2. Active learning process - its important that participants engage in course activities, and that they don't become the audience of a broadcast. A good course design allows for participants to engage with their peers in a large majority of the course steps.

4. An international learning experience - Our MOOCs have participants from all over the world taking part. Feedback from our courses has evidenced that having such a diverse and global cohort has opened their eyes to learning in a truly global context. For example in Introduction to Forensic Science, part of the course asks participants to research and report on DNA law and the use of DNA databases in their own countries, a topic that generated a lot of discussion and unearthed disparities in how various parts of the world use and view DNA evidence.

I think that technology has raised expectations for education but it has also provided exciting opportunities to meet them. In conclusion, I will leave you with the feedback from one of our MOOC participants:

"It was excellent - thanks again to everyone involved. Please can we have another murder."

\section{REFERENCES}

[1] Andrews, D., Hull, T., \& Donahue, J. (September 2009). Storytelling as an Instructional Method: Descriptions and Research Question. The Interdisciplinary Journal of Problem-Based Learning. 2(3), 6-23.

[2] Neuhauser, P. C. (1993). Corporate Legends and Lore: The Power of Storytelling as a Management Tool. McGraw-Hill.

[3] Parr, C. (2013) "Mooc completion rates 'below 7\%'" Times Higher Education, 9 May [Online]. Available at: http://www.timeshighereducation.co.uk/news/mooc-completion-rates-below7/2003710.article (Accessed: 5 June 2014). 